\title{
Bone Marrow Aplasia with Pancytopenia and Hemorrhage in a Japanese Black Calf
}

\author{
Morito FUKUNAKA ${ }^{1)}$, Yumi TOYODA ${ }^{2)}$,Yoshiyasu KOBAYASHI ${ }^{2)}$, Hidefumi FURUOKA ${ }^{2)}$ and Hisashi INOKUMA ${ }^{2) *}$ \\ ${ }^{1)}$ Tokachi Agricultural Mutual Aid Association, Kawanishi, Obihiro 089-1182 and ${ }^{2}$ School of Veterinary Medicine, Obihiro University of \\ Agriculture and Veterinary Medicine, Inada-cho, Obihiro, Hokkaido 080-8555, Japan
}

(Received 11 June 2010/Accepted 27 July 2010/Published online in J-STAGE 10 August 2010)

ABSTRACT. Severe leukopenia was incidentally found in a newborn Japanese Black calf by blood testing during the clinical trial of an iron dextran drug (day 1). At that time, no clinical problems were observed. On day 15, the calf presented with a high rectal temperature and tachypnea. Treatment with antibiotics and non-steroidal anti-inflammatory drugs did not improve clinical signs. Anemia, melena, and prolonged bleeding were also recorded. Necropsy findings revealed subcutaneous petechial hemorrhage and severe bone marrow aplasia. This is the first confirmed case of pancytopenia and hemorrhage associated with bone marrow aplasia in a Japanese Black calf. KEY WORDS: bone marrow aplasia, Japanese Black calf, pancytopenia.

Pancytopenia is the reduction of all cellular elements of blood, including red blood cells (RBCs), white blood cells (WBCs), and platelets. In cattle, there have been case reports of pancytopenia due to bone marrow necrosis [10], bone marrow depression by neoplastic lymphocyte infiltration [3], toxic protein derivatives from trichloroethyleneextracted soybean oil meal [7,9], drugs [1], and unknown congenital disorders [8]. A bleeding calf syndrome was recently reported in several European countries $[2,4,5]$. In the present report, we describe a clinical case of pancytopenia with bleeding caused by bone marrow aplasia in a Japanese Black calf.

In March 2008, leukopenia (WBCs, 1800/ $\mu l$; neutrophils, $1224 / \mu l$; lymphocytes, $576 / \mu l$ ) was incidentally found in a newborn Japanese Black calf by blood testing during the clinical trial of an iron dextran drug (day 1). At that time, the calf did not show any clinical problems and no drugs were administered other than $400 \mathrm{mg}$ iron dextran by intramuscular injection. RBC count $\left(11.17 \times 10^{6} / \mu l\right)$, hemoglobin concentration $(14.0 \mathrm{~g} / \mathrm{d} l)$, packed cell volume $(45 \%)$, and platelet count $(199,000 / \mu l)$ were within normal ranges. Given the abnormal blood test results, the calf was carefully observed by the owner.

On day 15 , the calf presented with high rectal temperature $\left(41.1^{\circ} \mathrm{C}\right)$ and tachypnea. Pneumonia due to leukopenia was suspected and treated with antibiotics (penicillin and streptomycin) and a non-steroidal anti-inflammatory drug (flunixin meglumine), but clinical signs did not improve. Lethargy, melena, and prolonged bleeding were observed on day 16. The calf was transferred to the Animal Teaching Hospital at the Obihiro University of Agriculture and Veterinary Medicine on day 18.

During initial physical examination at the hospital, lethargy, high rectal temperature $\left(39.9^{\circ} \mathrm{C}\right)$, tachycardia $(140$ beats/min), pale mucous membranes, coughing, and melena were recorded. Petechial hemorrhage was observed on oral

\footnotetext{
* Correspondence to: Inokuma, H., Obihiro University of Agriculture and Veterinary Medicine, Inada, Obihiro, 080-8555 Japan. e-mail: inokuma@obihiro.ac.jp
}

mucosal membranes. Prolonged bleeding began immediately after venipuncture, and a hematoma was found at the blood collection site of the jugular vein. Hematologic examination of peripheral blood revealed nonregenerative anemia (RBC count, $5.76 \times 10^{6} / \mu l$; hemoglobin concentration, $7.1 \mathrm{~g} / \mathrm{d} l$; packed cell volume, $22.7 \%$; mean corpuscular volume, $39.4 \mathrm{fl}$ ), severe leukopenia (WBC count, 1,300/ $\mu$; neutrophils, 143/ $\mu l$; lymphocytes, $1,118 / \mu l 1)$, and severe thrombocytopenia (platelet count, 57,000/ $l$ ). Mild azotemia was also detected (blood urea nitrogen, $50.8 \mathrm{mg} /$ $\mathrm{d} l$; creatinine, $2.1 \mathrm{mg} / \mathrm{d} l$ ), but other hematologic parameters were normal (aspartate aminotransferase, $71 \mathrm{U} / l$; lactate dehydrogenase, $635 \mathrm{IU} / l$; total protein, $7.4 \mathrm{~g} / \mathrm{d} l$; albumin, $2.9 \mathrm{~g} / \mathrm{d} l)$. Activated partial thromboplastin time $(29.5 \mathrm{sec})$, prothrombin time $(14.1 \mathrm{sec})$, and fibrinogen concentration $(487 \mathrm{mg} / \mathrm{d} l)$ were all within normal ranges. Severe thrombocytopenia was suspected as the cause of hemorrhage.

The animal was euthanized on day 19. On pathologic autopsy, widespread subcutaneous hemorrhage was observed in the lower jaw, around the eyes, on the neck above the chest, and in the femoral region. In the mesenterium, rumen, reticulum, omasum, abomasum, and small and large intestines, hemorrhage was noted in the mucosa and submucosa. Petechial hemorrhage was observed on the heart, spleen, and kidney surfaces and the tracheal, urinary, and gall bladder mucosal surfaces. Round and polymorphic yellow-green pseudomembranes were present on the mucosa throughout the small intestines. The color of the bone marrow in the sternum, femur, and humerus had faded to pink, showing fatty marrow (Fig. 1). Histopathologic analysis revealed severe bone marrow aplasia characterized by few marrow cells and a predominance of fat cells (Fig. 2A). Granulocytes, erythroid precursors, and megakaryocytes were markedly reduced (Fig. 2B). Extramedullary hematopoiesis was noted in the kidney, liver, and spleen. Bone marrow aplasia was pathologically diagnosed based on these findings.

Peripheral blood testing on day 1 revealed low WBC and neutrophil counts immediately after birth, suggesting granu- 


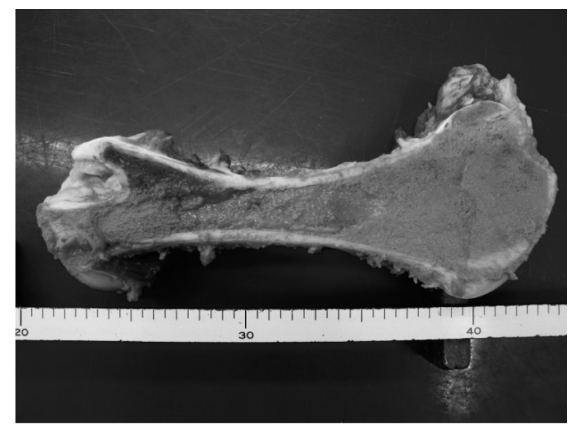

Fig. 1. Femoral bone marrow was pale pink.

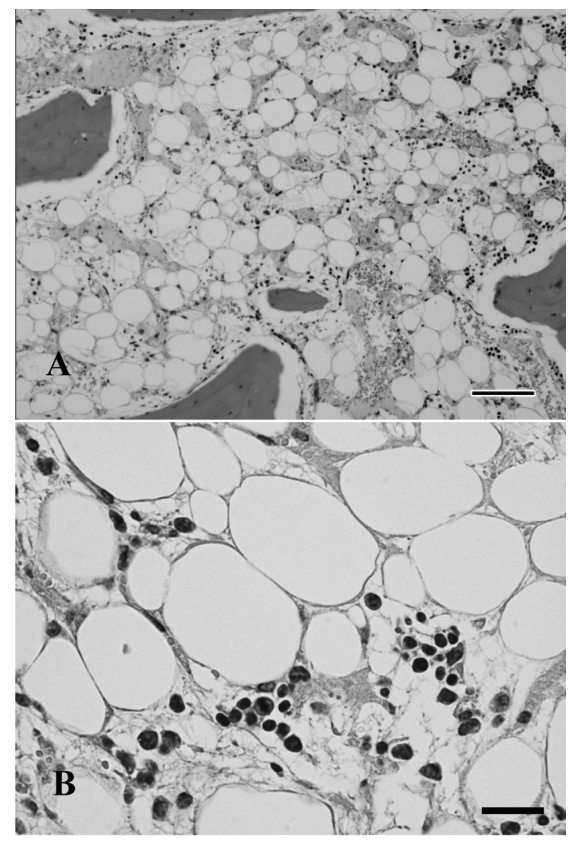

Fig. 2. (A) Histopathologic analysis of femoral bone marrow revealed severe bone marrow aplasia characterized by few marrow cells and a predominance of fat cells. (B) The remaining marrow cells included a small number of granulocytes, erythroid precursors, and megakaryocytes. Hematoxylin and eosin stain. Scale bars $=100 \mu \mathrm{m}$ in A, $25 \mu \mathrm{m}$ in B.

locytic hypoplasia. Because RBC and platelets counts were within normal ranges on day 1 , the bone marrow was likely damaged just before birth. Aplastic anemia has been reported in a 14-day-old Holstein calf and thought to have developed in utero [1]. An in utero toxic insult or infection may have affected the bone marrow of the calf in the present case, although its mother did not show any clinical abnormalities or receive drugs during delivery. Calf pancytopenia associated with bone marrow aplasia is the result of genetic predisposition, viral infection, or exposure to toxins, radiation, drugs, or chemicals. Bovine viral diarrhea virus (BVDV) is the most well-known cause of abnormal bone marrow in newborn calves [5]; however, results from reverse transcription-polymerase chain reaction (RT-PCR) analysis and a virus isolation test were negative for BVDV in this case. The involvement of other infectious factors was also unlikely, because no calves on the same farm or neighboring farms developed the disease during that period.

Ableeding calfsyndromewas recently reportedinEuropean countries $[2,4,6]$. The disease affects calves of different breeds and both sexes that are typically younger than 1 month old. Prominentclinical signsincludecutaneousbleeding, petechiae on all mucosae, melena, and high fever with a typical hematologic finding of pancytopenia [4]. Total bone marrow aplasia was the most prominent histologic finding [4]. The findings of the present case were similar to this disease, for which the cause is still unknown. In Japan, bone marrow aplasia has also been reported in a Holstein calf [8], although its association with the European bleeding calf syndrome is unclear. The present case is the first confirmed case of pancytopenia and hemorrhage associated with bone marrow aplasia in a Japanese Black calf. Careful observation of calves maybeneeded until it is known whether the breed is genetically predisposed to the disease.

ACKNOWLEDGMENTS. We thank the staff of Hokkaido Tokachi Livestock Hygiene Service Center for their technical assistance with the diagnosis of BVDV.

\section{REFERENCES}

1. Ammann, V. J., Fecteau, G., Helie, P., Desnoyer, M., Herbert, P. and Marie, B. 1996 Pancytopenia associated with bone marrow aplasia in a Holstein heifer. Can. Vet. J. 37: 493-495.

2. Freidrich, A., Rademacher, G., Weber, B. K., Kappe, E., Carlin, A., Assad, A., Sauter-Louis, C., Hafner-Maex, A., Buttner, M., Bottcher, J. and Klee, W. 2009. Increase in the incidence of a bleeding disorder in young calves due to bone marrow damage. Tiearztliche Umschau 64: 423-431.

3. McLaughlin, R. 1989. Aplastic anemia in a Holstein bull calf with lymphosarcoma. Bov. Pract. 24: 180-183.

4. Pardon, B., Steukers, L., Dierick, J., Ducatelle, R., Saey, V., Maes, S., Vercauteren, G., De Clercq, K., Callens, J., De Bleecker, K. and Deprez1, P. 2010. Haemorrhagic diathesis in neonatal calves: an emerging syndrome in Europe. Transboundary Emer. Dis. 57: 135-146

5. Perlerin, C., Van Der Hurk, J., Lecomte, J. and Tussen, P. 1994. Identification of a new group of bovine viral diarrhea virus strains associated with severe outbreaks and high mortalities. Virol. 203: 260-268.

6. Penny, C. D., Bell, C., Morrison, L., Howie, F. and Willoughby, K. 2009. Pancytopenia and haemorrhage in young beef calves. Vet. Rec. 164: 762.

7. Rundles, W. 1958. Toxic protein derivatives causing aplastic anemia; a review. Blood 13: 899-903.

8. Shimada, A., Onozato, T., Hoshi, E., Togashi, Y., Matsui, M., Miyake, Y., Kobayashi, Y., Furuoka, H., Matsui, T., Sasaki, N., Ishii, M. and Inokuma, H. 2007. Pancytopenia with bleeding tendency associated with bone marrow aplasia in a Holstein calf. J. Vet. Med. Sci. 69: 1317-1319.

9. Strafuss, A. C. and Sautter, J. H. 1967. Pathologic characteristics of renal lesions induced by S-(dichlorovinyl)-L-cysteine in calves and rats. Am. J. Vet. Res. 28: 25-37.

10. Weiss, D. J. and Miller, D. C. 1985. Bone marrow necrosis associated with pancytopenia in a cow. Vet. Pathol. 22: 90-92. 